\title{
Zingiber zerumbet L. (Smith) extract alleviates the ethanol-induced brain damage via its antioxidant activity
}

\author{
Asmah Hamid', Farah Wahida Ibrahim', Teoh Hooi Ming ${ }^{1}$, Mohd Nazir Nasrom', Norelina Eusoff', \\ Khairana Husain ${ }^{2}$ and Mazlyzam Abdul Latif ${ }^{*}$
}

\begin{abstract}
Background: Zingiber zerumbet (L.) Smith belongs to the Zingiberaceae family that is widely distributed throughout the tropics, particularly in Southeast Asia. It is locally known as 'Lempoyang' and traditionally used to treat fever, constipation and to relieve pain. It is also known to possess antioxidant and anti-inflammatory activities. Based on these antioxidant and anti-inflammatory activities, this study was conducted to investigate the effects of ethyl-acetate extract of $Z$. zerumbet rhizomes against ethanol-induced brain damage in male Wistar rats.

Method: Twenty-four male Wistar rats were divided into four groups which consist of normal, $1.8 \mathrm{~g} / \mathrm{kg}$ ethanol (40\% v/v), $200 \mathrm{mg} / \mathrm{kg}$ Z. zerumbet extract plus ethanol and $400 \mathrm{mg} / \mathrm{kg}$ Z. zerumbet plus ethanol. The extract of Z. zerumbet was given once daily by oral gavage, 30 min prior to ethanol exposure via intraperitoneal route for 14 consecutive days. The rats were then sacrificed. Blood and brain homogenate were subjected to biochemical tests and part of the brain tissue was sectioned for histological analysis.

Result: Treatment with ethyl-acetate Z. zerumbet extract at $200 \mathrm{mg} / \mathrm{kg}$ and $400 \mathrm{mg} / \mathrm{kg}$ significantly reduced the level of malondialdehyde (MDA) and protein carbonyl $(p<0.05)$ in the brain homogenate. Both doses of extracts also significantly increased the level of serum superoxide dismutase (SOD), catalase (CAT) and glutathione peroxidase (GPX) activities as well as glutathione (GSH) level $(p<0.05)$. However, administration of ethyl-acetate Z. zerumbet extract at $400 \mathrm{mg} / \mathrm{kg}$ showed better protective effects on the ethanol-induced brain damage as shown with higher levels of SOD, CAT, GPX and GSH in the brain homogenate as compared to $200 \mathrm{mg} / \mathrm{kg}$ dose. Histological observation of the cerebellum and cerebral cortex showed that the extract prevented the loss of Purkinje cells and retained the number and the shape of the cells.
\end{abstract}

Conclusion: Ethyl-acetate extract of $Z$. zerumbet has protective effects against ethanol-induced brain damage and this is mediated through its antioxidant properties.

Keywords: Zingiber zerumbet, Ethanol, Brain damage, Antioxidant, Oxidative stress

\section{Background}

Alcohol is a commonly abused substance worldwide that generates reactive oxygen species (ROS) whether it is consumed acutely or chronically [1]. Alcohol can easily cross the cell membranes, including the blood-brain barrier. Although it is metabolized mainly in the liver, it

\footnotetext{
* Correspondence: mazlyzam@ukm.edu.my

${ }^{1}$ Biomedical Science Programme, Centre of Health \& Applied Sciences, Faculty of Health Sciences, Universiti Kebangsaan Malaysia, Jalan Raja Muda Abdul Aziz, 50300 Kuala Lumpur, Malaysia
}

Full list of author information is available at the end of the article also causes toxic effects to the brain [2]. As the brain is rich in lipid content, it has high oxygen demand and lacks antioxidant activities thus very susceptible to oxidative stress as the brain easily undergo redox-reaction leading to radicals formation [3].

Alcohol causes oxidative damage by producing superoxide, hydroxyl and hydroethyl radicals which may contribute to lipid peroxidation, protein carbonyl formation and DNA damage [4]. Furthermore, it can disrupt the antioxidant system to cause oxidative stress [5] which eventually leads to neuronal cell death [6]. In normal 
condition, ROS and antioxidants are in a balanced state. Oxidative stress occurs when oxidants and antioxidants are in imbalance [7] either caused by excessive ROS or antioxidant system dysfunction [8]. Antioxidants are used to scavenge ROS [9].

Ethanol consumption has been associated with brain damage. Necropsy examinations of chronic alcoholics have shown a variety of structural and functional alterations in the neurons [10]. One brain region that is particularly sensitive to early ethanol exposure is the cerebellum. Previous study was found that 2 days of highly condensed alcohol exposure during neonatal brain growth resulted in Purkinje cell loss [11].

Zingiberaceae family is distributed widely in Asia where 50 genera and more than 1000 species can be found in this family including Curcuma longa which produces curcumin. Curcumin has been reported to have high antioxidant activities that protect the brain against ethanol-induced brain damage [1, 12]. Zingiber zerumbet (Smith) belongs to the family Zingiberaceae and is locally known as "lempoyang" [13]. Z. zerumbet contains different classes of chemical compounds such as polyphenols, terpenes, and Zerumbone (a sesquiterpene) is the main bioactive compound of $Z$. zerumbet [14].

Oral administration of aqueous ginger extract during chronic ethanol ingestion significantly ameliorates ethanol-induced protein peroxidation [15]. The antioxidant protective properties of polyphenol and flavonoid components of the extract possibly increase the antioxidative defence mechanism of the cells. Zingiber officinale extract was a potential brain tonic to enhance cognitive function for ethanol-related cognitive deficits [16]. The plant extract was found to exhibit protective capability and cognitive enhancing properties in ethanol-induced rats. It was also shown that $Z$. officinale at the dose of $200 \mathrm{mg} / \mathrm{kg}$ body weight could protect the brain against ischemic brain damage and reduced cognitive deficits in a rat model of focal cerebral ischemia induced by the occlusion of the right middle cerebral artery. This family of ginger was found to reduce the brain infarct volume and decrease oxidative stress in the cerebral cortex and hippocampus. Neuroprotective effect of $Z$. officinale extract might be related to its antioxidant effect.

Our previous study demonstrated that administration of $Z$. zerumbet ethyl acetate extract at 200 or $400 \mathrm{mg} / \mathrm{kg}$ displayed protective effects and antioxidant activities against paracetamol-induced nephrotoxicity. This was shown by increased in both antioxidant SOD and GSH level and reduction of both homogenate and plasma MDA, plasma protein carbonyl, and renal advanced oxidation protein product (AOPP) than those in the paracetamol induced group [17].
Another study on oral administration of ethyl acetate extract of $Z$. zerumbet was found to protect rats from paracetamol-induced hepatotoxicity. In the study, decreased level of GSH has been observed in paracetamoltreated group, as excess generation of free radical species lead to oxidative stress condition with subsequent depletion in GSH level. However, Z. zerumbet administration appeared to cause less oxidative stress condition as its ability to reduce protein and lipid oxidation and increase the antioxidant defense mechanism. Remarkable protective effects were observed at $400 \mathrm{mg} / \mathrm{kg}$ as compared to a lower dose of $200 \mathrm{mg} / \mathrm{kg}$ of the extract. This indicates that the amount of antioxidant compounds present in $Z$. zerumbet contributes significantly to its antioxidant property [18].

The rhizomes of $Z$. zerumbet are used to treat ulcerative colitis [19] to cure dyspepsia wound, hemorrhoids, and stomach discomfort [20]. Z. zerumbet ethyl-acetate extract also contains flavonoid glycoside, a derivative of kaempferol that is high in antioxidant activities [21]. However, to date, evidence on the neuroprotective effects of $Z$. zerumbet rhizomes is still lacking. Thus, the aim of this study is to investigate the protective effects of the ethyl-acetate extract of $Z$. zerumbet rhizomes against ethanol-induced brain damage in male Wistar rats.

\section{Methods}

\section{Plant extraction}

Zingiber zerumbet rhizomes were supplied from herbs farm (Kizaherbs Sdn Bhd) in Temerloh, Pahang, Malaysia. The plant was identified by a botanist and herbarium curator, Mr. Ahmad Damanhuri Mohamad from School of Environmental and Natural Resource Sciences and deposited at the Faculty of Science and Technology Herbarium, Universiti Kebangsaan Malaysia. It was given a voucher specimen number UKMB-29952. The air dried rhizomes of $Z$. zerumbet were soaked in $n$-hexane for $72 \mathrm{~h}$ at room temperature. This process was repeated three times. The rhizomes then underwent similar process with ethyl acetate followed by methanol. Each crude extract of hexane, ethyl-acetate and methanol was filtered and evaporated using rotary evaporator. The yielded extracts were subjected to dryness in a fume hood. The crude extracts were then stored at $4{ }^{\circ} \mathrm{C}$ until tested for bioassay. Prior to use, ethyl-acetate extract of $Z$. zerumbet was dissolved in di-methyl sulfoxide (DMSO) and diluted in phosphate buffered saline (PBS) $\mathrm{pH} 7.4$.

\section{Animals and treatment}

A total of 24 male albino Wistar rats were obtained from Laboratory Animal Resources Unit, Universiti Kebangsaan Malaysia (UKM). They were kept under standard laboratory conditions in a $12 \mathrm{~h}$ light/dark 
cycle with food and water provided ad libitum. The experiment involving the animals was approved according to animal handling guidelines provided by the UKM Animal Ethics Committee (FSK/BIOMED/2012/ASMAH/ 21-NOV/475-NOV-2012-JUNE-2013).

The animals were randomly divided into four groups with six rats in each group. Rats in Group 1 received normal saline (normal), Group II were ethanol-induced group where ethanol was administrated intraperitoneally at the dose of $1.8 \mathrm{~g} / \mathrm{kg}^{-1}(40 \% \mathrm{v} / \mathrm{v})$. Group III and IV were given the extract of $Z$. zerumbet via oral gavage at the doses of $200 \mathrm{mg} / \mathrm{kg}$ and $400 \mathrm{mg} / \mathrm{kg}$ respectively, $30 \mathrm{~min}$ prior to ethanol exposure, for 14 consecutive days. After 14 days, the rats were anaesthetized with a cocktail of ketamine, xylazil and zoletil $(0.5 \mathrm{ml} / \mathrm{kg}$ body weight) given intramuscular [22] and sacrificed through decapitation according to approved guidelines from UKM Animal Ethics Committee.

\section{Sample preparation}

Blood was collected by cardiac puncture in plain tubes and centrifuged at $3000 \mathrm{rpm}$ for $10 \mathrm{~min}$ to obtain serum. Serum samples were stored at $-20{ }^{\circ} \mathrm{C}$ for subsequent biochemical analysis. Brain samples were washed with normal saline and homogenized in cold $1.15 \%$ potassium chloride (KCI) (3 $\mathrm{ml} / \mathrm{g})$ using Ultra Turrax T25 homogenizer (IKA, Germany).

\section{Biochemical analysis}

Malondialdehyde (MDA) level is an index to determine lipid peroxidation process (Ledwozyw et al. 1986) [23]. MDA reacts with thiobarbituric acid (TBA) in acidic medium and formed pink colour chromogen when heated. Butanol was used to extract this chromogen and its absorbance was measured spectrophotometrically at the wavelength of $532 \mathrm{~nm}$.

Protein carbonyl level was determined according to a method as described by Levine [24] based on the reaction of carbonyl compounds with 2, 4-dinitrophenyl hydrazine (DNPH). Trichloroacetic acid (TCA) was used to precipitate the protein. The precipitated protein was centrifuged to form pellet. The procedure was followed by two steps of washing using ethanol/ethyl-acetate that would remove lipids from the protein pellet. The released protein carbonyl compounds were measured at the wavelength of $375 \mathrm{~nm}$.

SOD activity was assayed based on the procedure described by Beyer \& Fridovich [25]. This assay was based on the reduction of nitro blue tetrazoleum (NBT) by superoxide anion to form diformazan and the absorbance was measured with a spectrophotometer at $560 \mathrm{~nm}$ wavelength. One unit of SOD is described as the amount of SOD enzymes needed to inhibit the NBT reduction by $50 \%$ in $1 \mathrm{~min}$. CAT activity was measured by Aebi method [26] and its principle was based on the ability of CAT enzymes to catalyze the reduction of $\mathrm{H}_{2} \mathrm{O}_{2}$ to $\mathrm{O}_{2}$. Decomposition of $\mathrm{H}_{2} \mathrm{O}_{2}$ by CAT enzymes was measured at $240 \mathrm{~nm}$ wavelength.

GPx enzyme activity was assayed according to the procedure described by Paglia \& Valentine [27] based on the oxidation rate of glutathione (GSH) by $\mathrm{H}_{2} \mathrm{O}_{2}$ in the presence of GPx. Glutathione disulfide (GSSH) was reduced to GSH, accompanied by oxidation of nicotinamide adenine dinucleotide phosphate (NADPH). NADPH oxidation was measured at $340 \mathrm{~nm}$ wavelength and one unit of GPx is interpreted as one mole of NADPH required to be oxidized to NADP. GSH was quantified according to the protocols as described by Ellman [28]. GSH oxidation by 5, 5-dithiobis-2-nitrobenzoic (DTNB) reagent to form yellow-coloured complexes (TNB) was measured at the wavelength of $420 \mathrm{~nm}$.

\section{Histological analysis}

Brain tissues samples were fixed in 10\% formalin and dehydrated in an ascending series of alcohol concentration $(50 \%$ to $100 \%)$ and then embedded in paraffin blocks. The blocks were cut into $5 \mu \mathrm{m}$ sections using a microtome, fixed on slides followed with hematoxylin and eosin $(\mathrm{H} \& \mathrm{E})$ staining. The prepared slides were observed under light microscope (Olympus BX41 Japan).

\section{Statistical analysis}

Statistical analysis was performed by using Statistical Package for the Social Sciences (SPSS) version 19. Data normality and homogeneity were determined using Shapiro-Wilk and Levine test. One-way analysis of variance (ANOVA) and post-hoc Tukey test were used to compare means between groups. Data were expressed as mean \pm standard error of mean (SEM).

\section{Results}

Effects of $Z$. zerumbet extract on oxidative stress markers MDA level

A significant increased $(p<0.05)$ level of MDA was observed in brain samples of ethanol-induced group as compared to the normal group. Supplementation with $Z$. zerumbet extracts at $200 \mathrm{mg} / \mathrm{kg}$ and $400 \mathrm{mg} / \mathrm{kg}$ significantly decreased $(p<0.05)$ MDA levels compared to the ethanol-induced group (Fig. 1a).

\section{Protein carbonyl level}

Administration of ethanol alone caused a significant increase $(p<0.05)$ in protein carbonyl level in the brain samples compared to the normal group. However, protein carbonyl levels were found to be significantly lower $(p<0.05)$ in both $Z$. zerumbet treated group $(200 \mathrm{mg} / \mathrm{kg}$ 


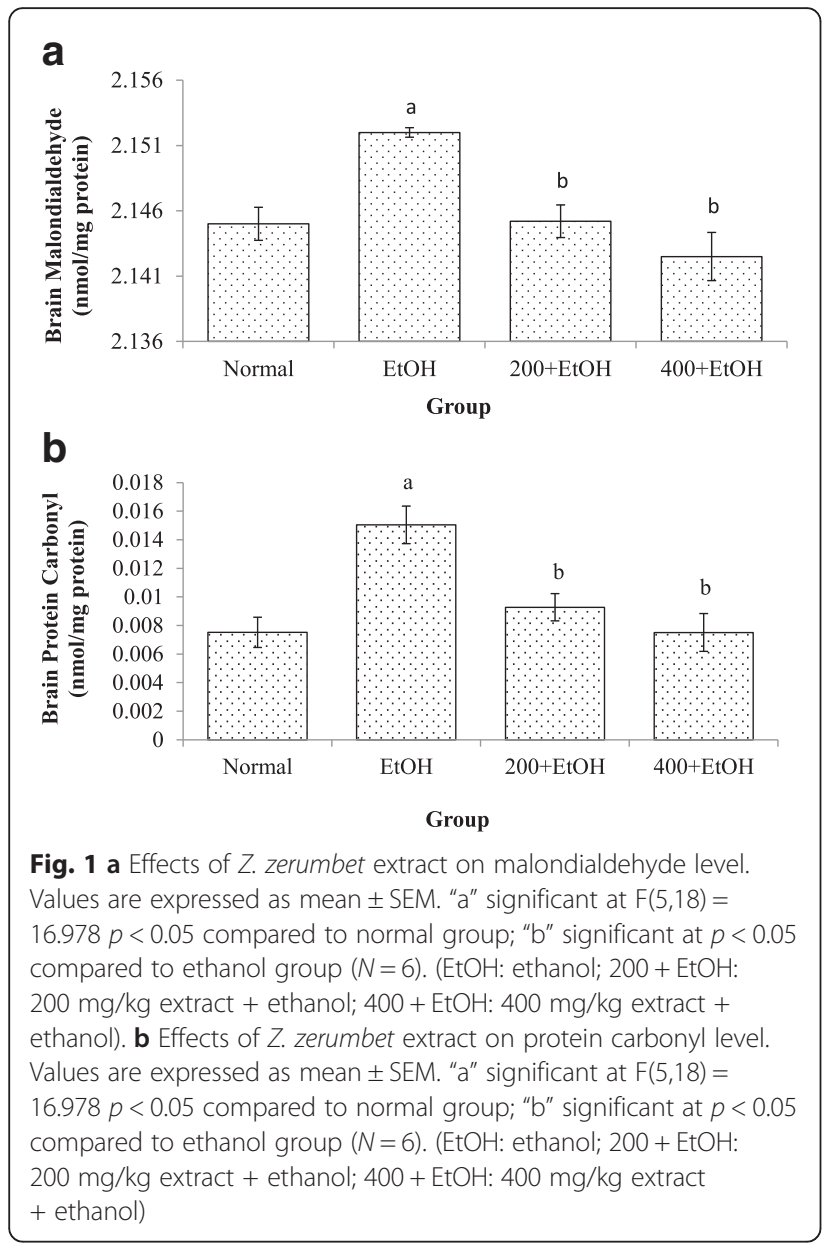

and $400 \mathrm{mg} / \mathrm{kg}$ ) as compared to the ethanol-induced group (Fig. 1b).

\section{Effects of $Z$. zerumbet extract on antioxidant status (SOD, CAT, GPx \& GSH)}

Administration of ethanol for 14 days induced oxidative stress as evidenced by a significant reduction $(p<0.05)$ of SOD, CAT and GPx enzyme activities (Fig. 2a-f) in both serum and brain samples. Treatment with $Z$. zerumbet extract at $200 \mathrm{mg} / \mathrm{kg}$ and $400 \mathrm{mg} / \mathrm{kg}$ significantly increased $(p<0.05)$ the SOD, CAT and GPx enzyme activities in serum samples. For the brain samples, only $400 \mathrm{mg} / \mathrm{kg} \mathrm{Z}$. zerumbet extract showed significant increased $(p<0.05)$ in the activities of these three enzymes as compared to the ethanol-induced group. Besides that, GSH level was significantly decreased ( $p<$ $0.05)$ in ethanol-induced group as compared to the normal group (Fig. 2g). For $400 \mathrm{mg} / \mathrm{kg} \mathrm{Z}$. zerumbet treated groups, there was a significant increment $(p<0.05)$ in the GSH level but $200 \mathrm{mg} / \mathrm{kg} \mathrm{Z}$. zerumbet treated group showed no significant difference $(p>0.05)$ compared to the ethanol group.

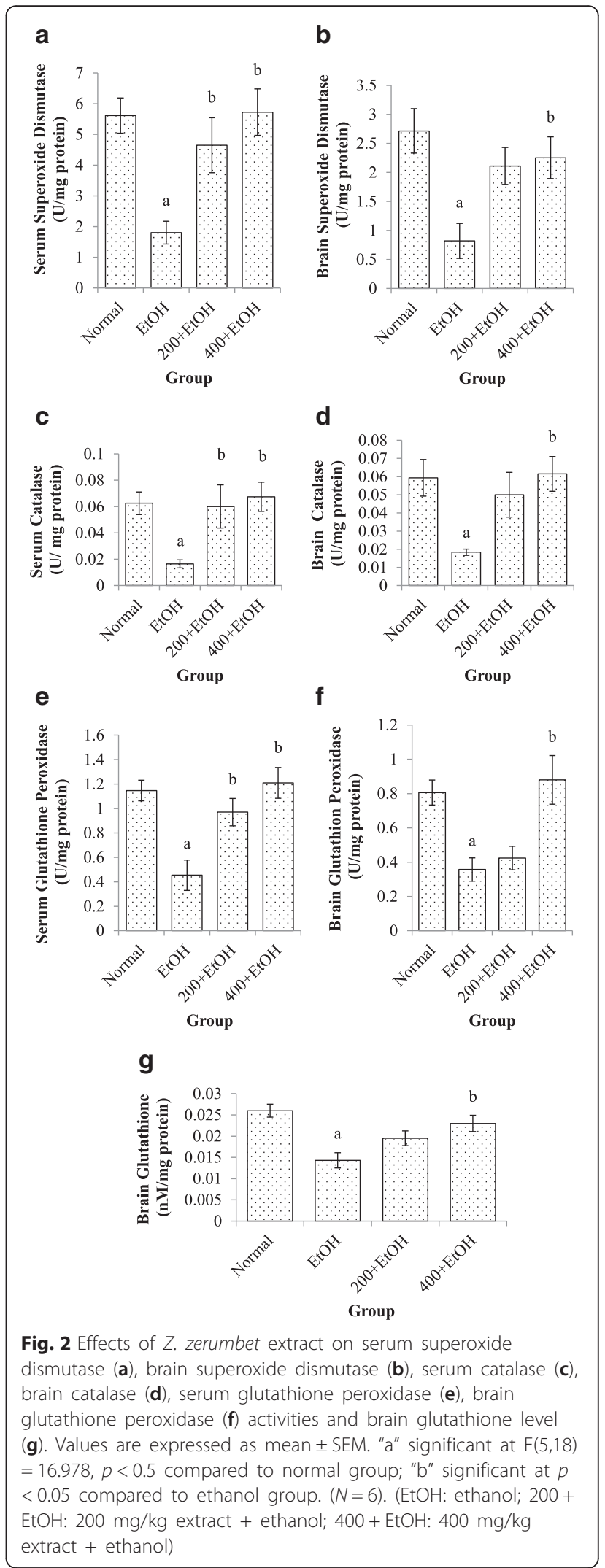




\section{Effects of Z. zerumbet extract on histological features of the brain}

Microscopic structures of the brain (cerebellum and cortex cerebrum) from normal, ethanol, $200 \mathrm{mg} / \mathrm{kg}+$ ethanol, and $400 \mathrm{mg} / \mathrm{kg}$ + ethanol groups were observed as presented in Figs. 3 and 4. Figure 3a showed that no histological changes were observed in the normal, $200 \mathrm{mg} / \mathrm{kg}$ + ethanol, and $400 \mathrm{mg} / \mathrm{kg}$ + ethanol groups as evidenced by normal Purkinje cells in the cerebellum (Fig. 3) and normal neuron cells in the cerebral cortex (Fig. 4). On the other hands, brain sections from ethanol-induced group showed that the distance between 2 Purkinje cells was large as compared to normal group. Neuron cells in in the cerebral cortex undergo necrosis with pyknotic characteristic such as darken nucleus and lost its morphology.

\section{Discussion}

Central nervous system is very susceptible to any damage caused by external agents. Brain is rich in polyunsaturated fatty acids and iron. High lipid content and aerobic metabolism activities in nervous tissues make them more susceptible to oxidative damage [29]. Furthermore, lack of antioxidant activities (CAT, SOD and GPx) in the brain also make it more susceptible to damage caused by ROS. Oxidative stress is caused by an imbalance of redox state in the cell, either excess ROS or defect in the antioxidant system [8]. Oxidative stress induced by short-term alcohol-intake [30] ultimately lead to neuronal cell death [6]. Ethanol dosage used in this study was selected based on the previous study [12] that showed protective effects of Coscinium fenestratum against ethanol-induced neurodegeneration in adult rat brain.

Cerebellum is responsible for coordinating muscle activities and maintaining body posture and balance. Cerebral cortex consists of three levels; molecular layer, granular layer and a layer of Purkinje. In addition, cerebral cortex is the outermost layer of the cerebrum and contains billion of neurons that play a role in memory, intelligence and muscle movement [31]. Neuronal cells are highly dependent on glucose for ATP generation and the production of ROS as a product of oxidative phosphorylation in the mitochondria. The resulting ROS production causes the imbalance between antioxidant and oxidative stress, that eventually will lead to neuronal cell damage [32]. That is why both cerebral cortex and cerebellum are the main target in this study.

Elevation of MDA level showed that alcohol produced ROS and caused oxidative stress in the brain. The ability of alcohol to induce lipid peroxidation is associated with direct or indirect damage caused by ethanol or acetaldehyde. Lipids are biomolecules that often become the target of oxidative stress and its oxidation will produce many secondary products such as MDA. Increased in the lipid peroxidation is represented by an increase in

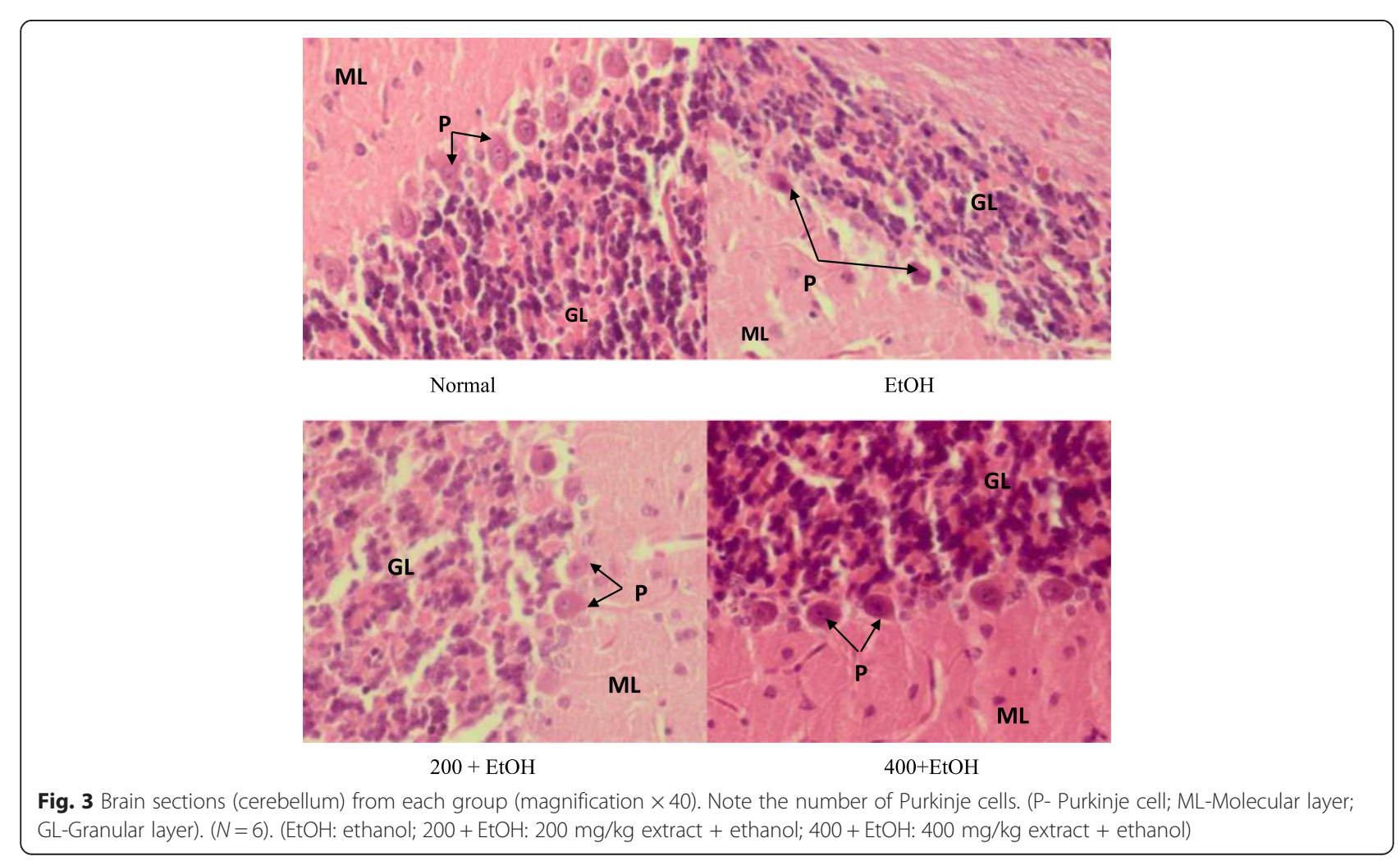



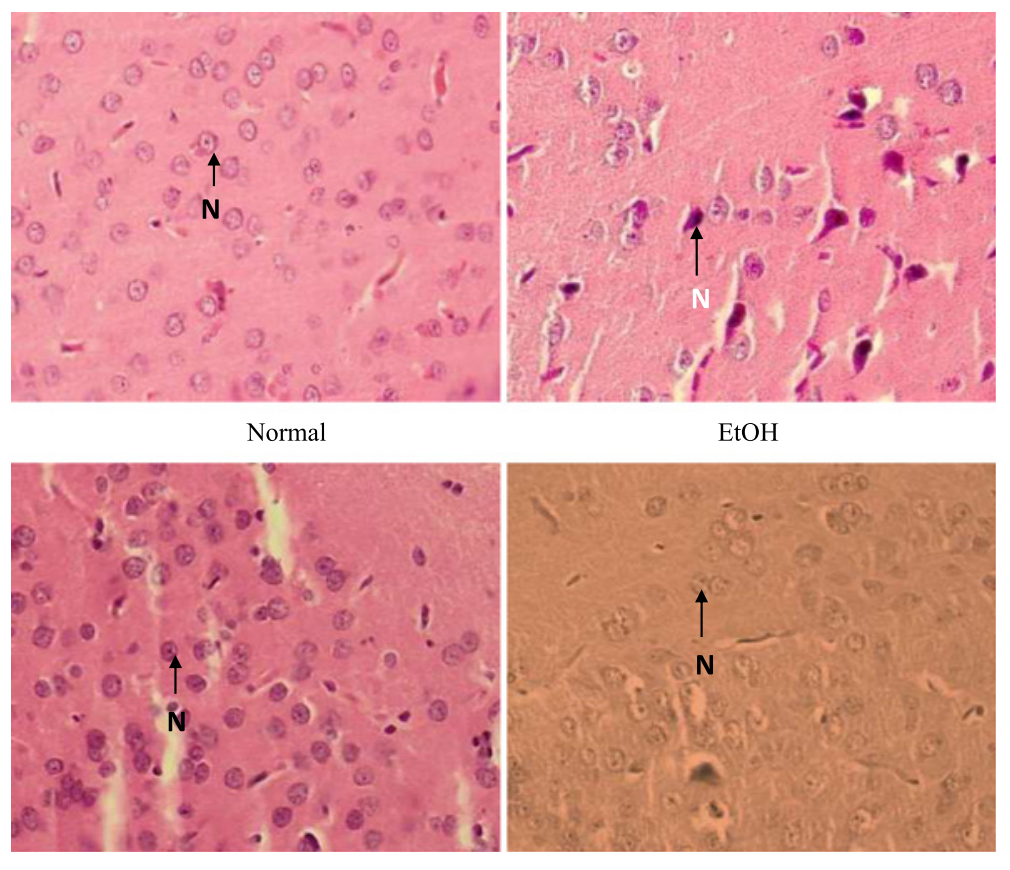

$200+\mathrm{EtOH}$

$400+\mathrm{EtOH}$

Fig. 4 Brain sections (cerebral cortex) from each group (magnification X40). Note the number and shape of neuron cells. ( $N$-Neuron cell). ( $N=6)$. (EtOH: ethanol; $200+\mathrm{EtOH}: 200 \mathrm{mg} / \mathrm{kg}$ extract + ethanol; $400+\mathrm{EtOH}: 400 \mathrm{mg} / \mathrm{kg}$ extract + ethanol)

the MDA concentration, which is a good biomarker for oxidative stress in the brain [3]. Besides that, protein is also one of the targets of ROS and its oxidation will cause protein to lose its functions. Protein carbonyl level is an indicator of protein damage that can be measured after alcohol consumption.

In contrast, treatment with $Z$. zerumbet extract $(200 \mathrm{mg} / \mathrm{kg} \& 400 \mathrm{mg} / \mathrm{kg}$ ) reduced the MDA and protein carbonyl levels in the brain. The ability of $Z$. zerumbet to protect brain tissues from lipid peroxidation and protein oxidation is in agreement with Hamid et al. [18] and Abdul Hamid et al. [17] studies, where supplementation of $Z$. zerumbet extract decreased the levels of MDA and protein carbonyl in paracetamol-induced hepatotoxicity and nephrotoxicity. These studies also supported that $Z$. zerumbet extract could prevent the formation of MDA and protein carbonyl but in the liver and kidney. Z. zerumbet ethyl-acetate extract contained flavonoid glycoside, one of kaempferol derivative that was characterized by radical scavenging activity and lipid peroxidation inhibition [21]. Zerumbone, the active compound of $Z$. zerumbet rhizomes protected the kidney against cisplastin-induced nephrotoxicity by blocking the MDA formation [33].

SOD is an antioxidant enzyme that catalyzes the conversion of anion superoxide $\left(\mathrm{O}_{2} \bullet^{-}\right)$to oxygen $\left(\mathrm{O}_{2}\right)$ and hydrogen peroxide $\left(\mathrm{H}_{2} \mathrm{O}_{2}\right)$. Reduction of SOD activity in the brain induced by ethanol in this study may be due to the generation of excessive anion, $\left(\mathrm{O}_{2}^{--}\right)$that causes this enzyme to become inactivated. CAT enzyme involves in the conversion of $\mathrm{H}_{2} \mathrm{O}_{2}$ to $\mathrm{H}_{2} \mathrm{O}$ and $\mathrm{O}_{2}$. The current study showed that ethanol decreased CAT activity in the brain after 14 days of alcohol exposure. This suggest that the decreased in the CAT activity may be due to the loss of nicotinamide adenine dinucleotide phosphate (NADPH), anion $\left(\mathrm{O}_{2}^{\circ-}\right)$ production and lipid peroxidation [34].

This study showed that $Z$. zerumbet extract administration increased the activities of SOD and CAT in the serum and brain homogenate. Zerumbone, an active compound isolated from rhizomes of $Z$. zerumbet could inhibit the production of anion $\mathrm{O}_{2}^{--}$in both NADPH oxidase and xanthine oxidase in acute promyelocytic leukemia cells and AS52 Chinese hamster ovary cells, respectively [35]. Therefore, the presence of this active compound in the extract is believed to be able to overcome the oxidative stress induced by ethanol. Furthermore, the antioxidant activity of $Z$. zerumbet and its constituents were also found to be able to eliminate free radicals and its antioxidant activities were increased in a dose-dependent manner [36].

GPx enzyme is responsible for detoxifying $\mathrm{H}_{2} \mathrm{O}_{2}$ by converting it to $\mathrm{H}_{2} \mathrm{O}$ in which GSH acts as an electron donor in this reaction [37]. On the other hand, GSH is a non-enzymatic antioxidant that serves to prevent oxidative damage caused by ROS. Impairment in GSH cellular defence mechanisms leads to the development of oxidative stress [38]. It also acts as a nucleophilic scavenger of toxic compounds and as a substrate in the reaction of 
other antioxidants (GPx uses GSH as a cofactor) [39]. In the current study, ethanol administration decreased GPx activity and GSH level both in serum and brain homogenate. ROS produced by ethanol exposure for 14 days probably deactivated both GPx and GSH enzyme activities [34].

However, administration of Z. zerumbet extract appeared to reduce oxidative stress induced by ethanol as evidenced by increased level of GSH in the brain. Zerumbone indirectly induced the GSH synthesis and provided intracellular protection mechanism to remove free radicals from toxic agents [33]. Thus, it could be speculated that Z. zerumbet extract may induce GSH synthesis by protecting the brain against ethanolinduced damage through similar mechanism. Zerumbone isolated from the rhizomes of $Z$. zerumbet could reduce the accumulation of MDA and increased GSH and GSH reductase (GR) activities against UVB-induced photokeratitis in mice [40] . In addition, Hamid et al. [18] and Abdul Hamid et al. [17] also reported that ethylacetate extract of $Z$. zerumbet could increase SOD and GSH activities in paracetamol-induced hepatotoxicity and nephrotoxicity in rats. Thus, Z. zerumbet extract is proven not only to increase the antioxidant enzyme activities in the liver and kidney but also in the brain.

Z. zerumbet extract at $400 \mathrm{mg} / \mathrm{kg}$ dose gave a better protective effect against ethanol-induced brain damage and this may be due to the high amount of zerumbone present in the extract. Increased SOD, CAT and GPx activities in this study may relate to the fact that the high antioxidant activities in Z.zerumbet extract induced endogenous antioxidant thus reduced the free radical activity [41]. In addition, an increase in the antioxidant activity can be described as an adaptive response to excessive ROS [42]. Although enzymatic activities of SOD, CAT, GPx and GSH in the $Z$. zerumbet treated group $(200 \mathrm{mg} / \mathrm{kg})$ were increased, but the increment were non-significant. Most probably, the $200 \mathrm{mg} / \mathrm{kg}$ of $Z$. zerumbet extract was insufficient to overcome the ROS generated by the ethanol induction. For the histological observation of the cerebellum, this study showed that the distance between any two Purkinje cells was larger in ethanol-induced rats, but a detailed and systematic calculation of the distance is required to be carried out to elucidate this issue.

Necrosis was observed in neuron cells (cerebral cortex) of ethanol-induced group with pyknotic characteristic such as darken nucleus and loss of its normal shape under light microscope. This characteristic is in agreement with Phachonpai et al. [12] that demonstrated ethanol administration at the dose of $1.8 \mathrm{~g} / \mathrm{kg}$ via intraperitoneal for 14 days caused neurodegeneration in the cerebral cortex. Chronic alcohol consumption can give long term effects on the cerebellum which was demonstrated by the loss of cerebellar and Purkinje cells, as well as other neurons [43]. A qualitative study found that there was a loss of Purkinje cells in the vermis with a reduction by $43 \%$ on average [44]. One study also reported ethanol administration did induced brain damage [45]. Significant brain damage in adults is found in limbic association regions and in these regions, dark cell degeneration, a necrotic cell death is the predominant form of neuronal death [46]. In contrast, concurrent treatment with $Z$. zerumbet extract, protected cerebellum and cerebral cortex against ethanolinduced brain damage as evidenced by no differences in the morphology of Purkinje cells and neuron cells in both Z. zerumbet extract treated rats $(200 \mathrm{mg} / \mathrm{kg}$ and $400 \mathrm{mg} /$ $\mathrm{kg}$ ) compared with the normal rats.

\section{Conclusion}

Based on this finding, $Z$. zerumbet ethyl-acetate extract is proven to possess protective effects against ethanolinduced brain damage in Wistar rats by decreasing lipid and protein oxidation as well as increasing antioxidant activities. This suggest that $Z$. zerumbet has the potential as a neuroprotective agent. Further studies are needed to explore its neuroprotective underlying mechanism.

\section{Abbreviations}

CAT: Catalase; DMSO: Di-methyl sulfoxide; DNPH: Dinitrophenyl hydrazine; GPx: Glutathione peroxidase; GSH: Glutathione; GSSH: Glutathione disulfide; $\mathrm{KCl}$ : Potassium chloride; MDA: Malondialdehyde; NADPH: Nicotinamide adenine dinucleotide phosphate; NBT: Nitro blue tetrazoleum; PBS: Phosphate buffered saline; ROS: Reactive oxygen species; SOD: Superoxide dismutase; TBA: Thiobarbituric acid; TCA: Trichloroacetic acid

\section{Acknowledgments}

We would like to thank our colleagues from Biomedical Science Programme, Centre of Health \& Applied Sciences, Faculty of Health Sciences, Universiti Kebangsaan Malaysia who provided insight and expertise that greatly assisted the research.

\section{Funding}

This work was financially funded by Ministry of Higher Education Fundamental Research Grant Scheme (FRGS/1/2013/SKK01/UKM/02/1) and Biomedical Science Programme, Centre of Health \& Applied Sciences, Faculty of Health Sciences, UKM

\section{Availability of data and materials}

All datasets used and/or analysed during the current study available from the corresponding author on reasonable request.

\section{Declarations}

All figures used in the graphical abstract are free from copyright.

\section{Authors' contributions}

$\mathrm{AH}, \mathrm{FWI}$ and THM conceived and designed the study. THM and $\mathrm{KH}$ prepared and analyzed the herbs. THM performed the in vivo study. THM, NE, MNN analyzed the data and wrote the manuscript. $\mathrm{AH}, \mathrm{FWI}$ and MAL reviewed the manuscript. All authors read and approved the final manuscript.

\section{Authors' information}

Associate Professor Asmah Hamid, Farah Wahida Ibrahim, Dr. Mazlyzam Abdul Latif, Teoh Hooi Ming, Mohd Nazir Nasrom, Norelina Eusoff: member of Biomedical Science Programme, Centre of Health \& Applied Sciences, Faculty of Health Sciences, Universiti Kebangsaan Malaysia, Kuala Lumpur, Malaysia and associate professor Khairana Husain: Faculty of Pharmacy, Universiti Kebangsaan Malaysia, Kuala Lumpur, Malaysia. 


\section{Ethics approval}

All procedures were approved by the Universiti Kebangsaan Malaysia Animal Ethics Committee (UKMAEC), Laboratory Animal Resource Unit, Faculty of Medicine, UKM, Jalan Raja Muda Abdul Aziz, Kuala Lumpur. Approved on 22nd November 2012 with estimated duration of project from November 2012 to June 2013. (FSK/BIOMED/2012/ASMAH/21-NOV/475-NOV-2012-JUNE-2013).

\section{Consent for publication}

Not applicable

\section{Competing interests}

The authors declare that they have no competing interests.

\section{Publisher's Note}

Springer Nature remains neutral with regard to jurisdictional claims in published maps and institutional affiliations.

\section{Author details}

'Biomedical Science Programme, Centre of Health \& Applied Sciences, Faculty of Health Sciences, Universiti Kebangsaan Malaysia, Jalan Raja Muda Abdul Aziz, 50300 Kuala Lumpur, Malaysia. ${ }^{2}$ Faculty of Pharmacy, Universiti Kebangsaan Malaysia, Jalan Raja Muda Abdul Aziz, 50300 Kuala Lumpur, Malaysia.

Received: 17 August 2016 Accepted: 8 March 2018 Published online: 20 March 2018

\section{References}

1. Wattanathorn J, Phunchago N, Muchimapura S, Thukhum-Mee W, Chaisiwamongkol K, Kaewrueng W, Wongareonwanakij S. Mulberry fruit mitigates alcohol neurotoxicity and memory impairment induced by chronic alcohol intake. Am J Appl Sci. 2012;9(4):484-91.

2. Mansouri A, Demeilliers C, Amsellem S, Pessayre D, Fromenty B. Acute ethanol administration oxidatively damages and depletes mitochondrial DNA in mouse liver, brain, heart, and skeletal muscles: protective effects of antioxidants. J Pharmacol Exp Ther. 2001;298(2):737-43.

3. Kruk-Slomka M, Boguszewska-Czubara A, Slomka T, Budzynska B, Biala G Correlations between the memory-related behavior and the level of oxidative stress biomarkers in the mice brain, provoked by an acute administration of CB receptor ligands. Neural Plast. 2016; https://doi.org/10. 1155/2016/9815092

4. Brocardo PS, Gil-Mohapel J, Christie BR. The role of oxidative stress in fetal alcohol spectrum disorders. Brain Res Rev. 2011;67:209-25.

5. Cohen-Kerem R, Koren G. Antioxidants and fetal protection against ethanol teratogenicity I. Review of the experimental data and implications to humans. Neurotoxicol Teratol. 2003;25(1):1-9.

6. Butterfield DA, Castegna A, Drake J, Scapagnini G, Calabrese V. Vitamin E and neurodegenerative disorders associated with oxidative stress. Nutr Neurosci. 2002;5(4):229-39.

7. Joseph JA, Shukitt-Hale B, Casadesus G, Fisher D. Oxidative stress and inflammation in brain aging: nutritional considerations. Neurochem Res. 2005;30(6-7):927-35.

8. Gandhi S, Abramov AY. Mechanism of oxidative stress in neurodegeneration. Oxidative Med Cell Longev. 2012; https://doi.org/10, $1155 / 2012 / 428010$

9. Goodlett CR, Horn KH, Zhou FC. Alcohol teratogenesis: mechanisms of damage and strategies for intervention. Exp Biol Med. 2005;230(6):394-406.

10. Lipnik-Štangelj M. Ethanol toxicity in the brain: alteration of Astroglial cell function. In: Gallelli L., editors. Pharmacology. InTech; 2012. p. 607-24. https://doi.org/10.5772/31366.

11. Thomas JD, Goodlett CR, West JR. Alcohol-induced Purkinje cell loss depends on developmental timing of alcohol exposure and correlates with motor performance. Brain Res Dev Brain Res. 1998;105(2):159-66.

12. Phachonpai W, Wattanathorn J, Wannanon P. Thipkaew C, Sripanidkulchai B, Muchimapura S. Coscinium Fenestratum protects against ethanol-induced neurodegeneration in adult in rat brain. Am J Pharmacol Toxicol. 2012;7(3):81-8.

13. Yob NJ, Joffry SM, Meor Mohd. Affandi MMR, Teh LK, Salleh MZ, Zakaria ZA. Zingiber zerumbet (L.) Smith: a review of its Ethnomedicinal, chemical, and pharmacological uses. Evid Based Complement Alternat Med. 2011; https:// doi.org/10.1155/2011/543216.
14. Koga AY, Beltrame FL, Pereira AV. Several aspects of Zingiber zerumbet: a review. Rev Bras. 2016;26(3):385-91.

15. Marella S, Reddy KS. Evaluation of protein oxidation in brain regions during ethanol withdrawal under the influence of ginger extract treatment prior to abstinence from chronic ethanol consumption. Eur J Biol Sci. 2012;4(4):136-45.

16. Maralla S, Reddy KS. Effect of aqueous extract of ginger on acetylcholine in brain and it's a possible role in learning and memory during ethanol withdrawal. Asian J Pharm Clin Res. 2014;7(Suppl 1):192-8.

17. Abdul Hamid Z, Budin SB, Wen Jie N, Hamid A, Husain K, Mohamed J. Nephroprotective effects of Zingiber zerumbet Smith ethyl acetate extract against paracetamol-induced nephrotoxicity and oxidative stress in rats. J Zhejiang Univ Sci B. 2012;13(3):176-85.

18. Hamid A, Budin SB, Mohamed RAP, Abd Manaf N, Yuhana NY, Husain K, Abdul Hamid Z, Mohamed J. Role of oxidative stress in the protective effects of Zingiber zerumbet Smith ethyl-acetate extract against paracetamol-induced hepatotoxicity in Sprague-Dawley rats. Aust J Basic Appl Sci. 2011;5(8):1519-25.

19. Sharifah Sakinah SA, Handayani ST, Azimahtol Hawariah LP. Zerumbone induced apoptosis in liver cancer cells via modulation of $\mathrm{Bax} / \mathrm{Bcl}-2$ ratio. Cancer Cell Int. 2007; https://doi.org/10.1186/1475-2867-7-4.

20. Rout OP, Acharya R, Kumar MS. Zingiber zerumbet (L.) Smith, a reservoir plant for therapeutic uses: a review. Int J Pharm World Res. 2011;2:1-23.

21. Ruslay S, Abas F, Shaari K, Zainal Z, Sirat H, Israf DA, Lajis NH. Characterization of the components present in the active fractions of health gingers (Curcuma xanthorrhiza and Zingiber zerumbet) by HPLC-DAD-ESIMS. Food Chem. 2007;104(3):1183-91.

22. Nayak S, Nalabothu P, Sandiford S, Bhogadi V, Adogwa A. Evaluation of wound healing activity of Allamanda cathartica. L. and Laurus nobilis. L. Extracts on rats. BMC Complement Altern Med. 2006; https://doi.org/10. 1186/1472-6882-6-12.

23. Ledwozyw A, Michalak J, Stepień A, Kadziołka A. The relationship between plasma triglycerides, cholesterol, total lipids and lipid peroxidation products during human atherosclerosis. Clin Chim Acta. 1986;155(3):275-83.

24. Levine RL, Garland D, Oliver CN, Amici A, Climent I, Lenz AG, Ahn BW, Shaltiel S, Stadtman ER. Determination of carbonyl content in oxidatively modified protein. Methods Enzymol. 1990;186:464-78.

25. Beyer WF, Fridovich I. Assaying for superoxide dismutase activity: some large consequences of minor changes in conditions. Anal Biochem. 1987; 161(2):559-66.

26. Aebi H. Catalase in vitro. Methods Enzymol. 1984;105:121-6.

27. Paglia DE, Valentine WN. Studies on the quantitative and qualitative characterization of erythrocyte glutathione peroxidase. J Lab Clin Med. 1967; 70(1):158-69.

28. Ellman GL. Tissue sulfhydryl groups. Arch Biochem Biophys. 1959;82(1):70-7.

29. Sun AY, Simonyi A, Sun GY. The 'French paradox' and beyond: neuroprotective effects of polyphenols. Free Radic Biol Med. 2002;32(4):314-8.

30. Harrison-Findik DD, Lu S. The effect of alcohol and hydrogen peroxide on liver hepcidin gene expression in mice lacking antioxidant enzymes, glutathione peroxidase-1 or catalase. Biomol Ther. 2015:5(2):793-807.

31. Tortora GJ, Derrickson B. The digestive system: absorption of alcohol. In: Tortora GJ, Derrickson B, editors. Principles of anatomy and physiology. New York: Wiley; 2005. p. 931.

32. Halliwel B. Reactive species and antioxidants. Redox biology is a fundamental theme of aerobic life. Plant Physiol. 2006;141(2):312-22.

33. Ibrahim MY, Abdul AB, Ibrahim TAT, Wahab SIA, Elhassan MM, Mohan S. Attenuation of cisplatin-induced nephrotoxicity in rats using zerumbone. Afr J Biotechnol. 2010;9(28):4434-41.

34. Das SK, Varadhan S, Dhanya L, Mukherjee S, Vasudevan DM. Effects of chronic ethanol exposure on renal function tests and oxidative stress in kidney. Indian J Clin Biochem. 2008;23(4):341-4.

35. Murakami A, Takahashi D, Kinoshita T, Koshimizu K, Kim HW, Yoshihiro A, Nakamura Y, Jiwajinda S, Terao J, Ohigashi H. Zerumbone, a southeast Asian ginger sesquiterpene, markedly suppresses free radical generation, proinflammatory protein production, and cancer cell proliferation accompanied by apoptosis: the $\alpha, \beta$-unsaturated carbonyl group is a prerequisite. Carcinogenesis. 2002;23(5):795-802

36. Sreevani N, Hafeeza K, Sulochanamma G, Pura Naik J, Madhava NM. Studies on antioxidant activity of Zingiber zerumbet spent and its constituents through in vitro models. Wudpecker J Food Technol. 2013;1 (3):48-55.

37. Aoyama K, Watabe M, Nakaki T. Regulation of neuronal glutathione synthesis. J Pharmacol Sci. 2008;108(3):227-38. 
38. Rains $\mathrm{L}$, Jain SK. Oxidative stress, insulin signaling, and diabetes. Free Radic Biol Med. 2011;50(5):567-75.

39. Forman HJ, Zhang H, Rinna A. Glutathione: overview of its protective roles, measurement, and biosynthesis. Mol Asp Med. 2009;30(1-2):1-12.

40. Chen BY, Lin DP, Wu CY, Teng MC, Sun CY, Tsai YT, Su KC, Wang SR, Chang $\mathrm{HH}$. Dietary zerumbone prevents mouse cornea from UVB-induced photokeratitis through inhibition of NF-kB, iNOS, and TNF-a expression and reduction of MDA accumulation. Mol Vis. 2011;17:854-63.

41. Nakamura Y, Yoshida C, Murakami A, Ohigashi H, Osawa T, Uchida K. Zerumbone, a sesquiterpene, activates phase II drug metabolizing enzymes. FEBS Lett. 2004:572(1-3):245-50.

42. Haorah J, Ramirez SH, Floreani N, Gorantla S, Morsey B, Persidsky Y. Mechanism of alcohol-induced oxidative stress and neuronal injury. Free Radic Biol Med. 2008;45(11):1542-50.

43. Davis KD, Taylor KS, Hutchison WD, Dostrovsky JO, McAndrews MP, Richter EO, Lozano AM. Human anterior cingulate cortex neurons encode cognitive and emotional demands. J Neurosci. 2005:25(37):8402-6.

44. Baker KG, Harding AJ, Halliday GM, Kril JJ, Harper CG. Neuronal loss in functional zones of the cerebellum of chronic alcoholics with and without Wernicke's encephalopathy. Neuroscience. 1999;91(2):429-38.

45. Crews FT, Nixon K. Mechanisms of neurodegeneration and regeneration in alcoholism. Alcohol Alcohol. 2009:44(2):115-27.

46. Obernier JA, Bouldin TW, Crews FT. Binge ethanol exposure in adult rats causes necrotic cell death. Alcohol Clin Exp Res. 2002;26(4):547-57.

Submit your next manuscript to BioMed Central and we will help you at every step:

- We accept pre-submission inquiries

- Our selector tool helps you to find the most relevant journal

- We provide round the clock customer support

- Convenient online submission

- Thorough peer review

- Inclusion in PubMed and all major indexing services

- Maximum visibility for your research

Submit your manuscript at www.biomedcentral.com/submit
Biomed Central 